\title{
Impact of inclined and perforated baffles on the laminar thermo-flow behavior in rectangular channels
}

\author{
Seyed Esmail Razavi ${ }^{1} \cdot{\text { Tohid } \text { Adibi }^{2} \text { [D }}^{-S a m a n}$ Faramarzi $^{1}$
}

Received: 30 August 2019 / Accepted: 21 January 2020 / Published online: 29 January 2020

(c) Springer Nature Switzerland AG 2020

\begin{abstract}
In this paper, incompressible thermo-flow is simulated for a channel and with and without baffles. A baffle is connected to the channel from different angles. The effect of perforated inclined baffles on the flow pattern and heat transfer in a channel investigated. The computations are based on the finite element method, Galerkin scheme, and Newton-Raphson iterative method have been implemented. The flow regime was assumed to be laminar. Results show that the use of perforated baffles leads to an increase in the Nusselt number and minimized friction factor in comparison to the plain ones. The numerical results are compared with the available solutions in the literature. The defined efficiency of the baffle is obtained for various baffle types, baffle's angle, Reynolds number, and baffle's ratios. The optimum angle of the baffle inclinations was obtained. It was found that perforated baffles demonstrate show superior performance when compared with plain counterparts. Also, there is local heat transfer enhancement at the downstream of the stepped baffle caused by the impinging effect of flow, which is even more significant when baffle height becomes higher or the Reynolds number elevates. Obtained results show that a $135^{\circ}$ perforated baffle is a better choice as it enhances the heat transfer with a minimal friction factor.
\end{abstract}

Keywords Navier-Stokes equations · Incompressible flow $\cdot$ Heat transfer $\cdot$ Perforated baffle

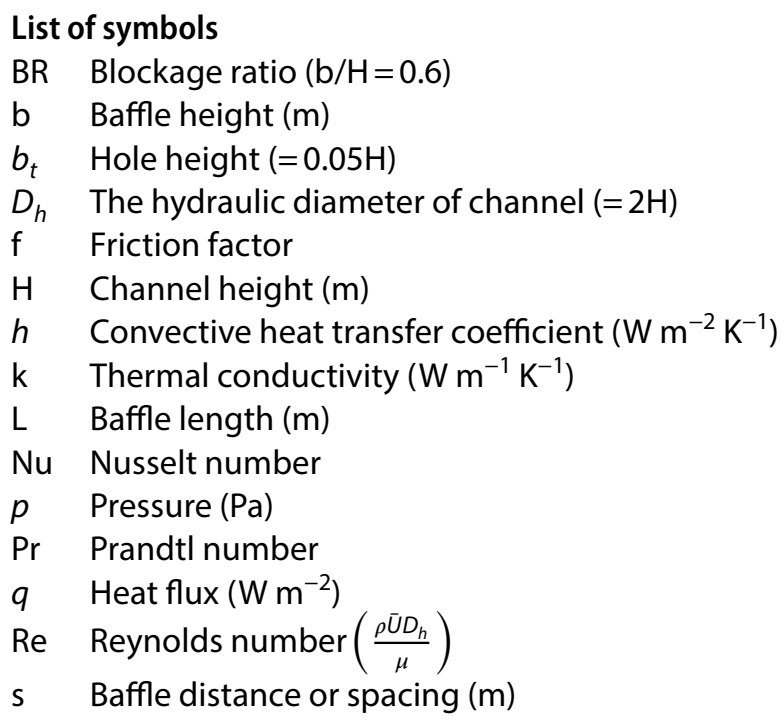

$S$ Spacing ratio $(\mathrm{s} / \mathrm{H})$

$\mathrm{T} \quad$ Temperature $(\mathrm{K})$

$u_{i} \quad$ Velocity in $x_{i}$-direction $\left(\mathrm{m} \mathrm{s}^{-1}\right)$

$\bar{u} \quad$ Mean velocity of the channel $\left(\mathrm{m} \mathrm{s}^{-1}\right)$

w Baffle width $(=0.02 \mathrm{H})$

Greek symbols

$\mu \quad$ Dynamic viscosity $\left(\mathrm{kg} \mathrm{s}^{-1} \mathrm{~m}^{-1}\right)$

$\Gamma \quad$ Thermal diffusivity

$\Phi \quad$ Baffle inclination angle $\left({ }^{\circ}\right)$

$\rho$ Density $\left(\mathrm{kg} \mathrm{m}^{-3}\right)$

\section{Subscripts}

$i, j$ Refers coordinate direction vectors in the inlet

0 Smooth channel

pe Perforated baffle

pl Plain baffle

Tohid Adibi, tohidadibi@bonabu.ac.ir | ${ }^{1}$ School of Mechanical Engineering, University of Tabriz, Tabriz, Iran. ${ }^{2}$ Department of Mechanical Engineering, University of Bonab, Bonab, Iran. 


\section{ra Ratio \\ w Wall}

\section{Introduction}

Baffles are used for heat transfer enhancement in the channels. Mounting of baffles in the channels alters the thermoflow behavior by inducing vortices. These vortices rise the heat transfer caused by a sudden change in geometry. Up to now, many heat transfer augmentation techniques have been utilized, such as perforated, inclined, and porous baffles, where most of them are based on the baffle configuration. However, mounting the baffles in channels leads to pressure drop. Achieving the minimized pressure drop along with elevated heat transfer has been the purpose of many kinds of research. Baffle spacing, angle of attack, and height have been found to be effective parameters to achieve high performance in thermal systems.

Armaly et al. [1] conducted experiments using LDV (Laser Doppler Velocimetry). They also included numerical predictions of backward-facing step flow by hybrid central-upwind-differencing embodied in TEACH code. The velocity distribution and reattachment length were obtained. Cheng and Huang [2] studied the effect of baffles in laminar forced convection in a horizontal channel by finite difference method and SIMPLE algorithm. They used the power-law scheme for the treatment of convection terms. Experimental investigation of Prashanta and Sandip [3] on size, perforation, and orientation of baffles was checked out to increase the heat transfer. They calculated friction factor and Nusselt number by using thermocouples and pressure taps. Lopez et al. [4] investigated laminar forced heat transfer in a three-dimensional channel with baffles at laminar flow with the SIMPLER algorithm and the power-law scheme. Miranda and Anand [5] studied the effect of solid and porous baffles by the control volume method and SIMPLEC algorithm. They linked convection and diffusion terms by the power-law scheme. It was found that the porous baffles have a better heat transfer rate at larger baffle spacing. Mousavi and Hooman [6] studied the heat transfer in the entrance region with large baffles in the laminar regime by the SIMPLER algorithm. The convection and diffusion terms have been linked by the power-law method. They reported that the Prandtl number affects the precise location of the periodically fully developed region. Nasiruddin and Siddiqui [7] studied heat transfer enhancement in a heat exchanger tube by installing a baffle. The effect of baffle size and orientation on the heat transfer was studied in detail by the SIMPLE algorithm. The second-order upwind scheme was used to calculate the derivatives of the flow variables. The governing equations were solved by an implicit iterative scheme. They reported that a significant heat transfer enhancement in a heat exchanger tube could be achieved by introducing an inclined baffle into the flow. Sripattanapipat and Promvonge [8] studied a two-dimensional channel with a staggered diamond-shaped baffle by the QUICK scheme and SIMPLE algorithm. Promvonge et al. [9] numerically studied the effect of the 45-angled baffle to examine laminar flow and heat transfer characteristics in a square channel. The governing equations were discretized by the second-order upwind differencing scheme and coupling with the SIMPLE algorithm. Gajusingh et al. [10] investigated the impact of a rectangular baffle inside a square channel using particle image velocimetry. Huang et al. [11] conducted an experimental investigation on the effects of the perforated baffle on heat transfer characteristics. They measured the variations of heat transfer coefficient at various Reynolds numbers by the transient liquid crystal method. Chompookham et al. [12] experimentally studied the effect of combined wedge ribs and winglet type vortex generators on heat transfer and friction factor behavior for turbulent airflow through a rectangular channel. They calculated friction factor and Nusselt number by using twelve thermocouples and two static pressure taps.

Benzenine et al. [13] simulated three-dimensional laminar convection in a rectangular channel with baffle attached to its lower wall numerically. The SIMPLE scheme is used in a finite volume method. Adibi et al. [14, 15] worked on mixed convection on the closed domain. A characteristic-based scheme was used for numerical simulations. Nusselt number was obtained in different conditions.

In this paper, a finite element model is used for incompressible laminar flows past two perforated inclined baffles. The velocity and temperature fields are solved by the Galerkin scheme and the Newton-Raphson method. Results showed that the solid baffle improves heat transfer and the use of a perforated baffle attached to the same position enhances heat transfer more.

- Meni et al. [16] simulated airflow in a channel with and without baffles numerically. FLUENT software was used for numerical simulation. Flat and s-shape baffles were considered in this work. Sahin et al. [17] Simulated flow in a heat sink with hollow trapezoidal baffles. Results showed that the most effective parameter on heat transfer is Reynolds number and baffle width and corner angle insignificant effect on Nusselt number. Foukrach and Ameur [18] studied the impact of the shape of the baffle on the flow characteristics numerically. The incompressible turbulent flow was simulated, and the optimum baffles were obtained. Shiriny et al. [19] studied incompressible nano-fluid flow numerically. Baffles were used in the channel to enhance the heat transfer rate. 
The present work aims to investigate and analyze the impact of several parameters variations (such as baffle tilt angle, perforation) on the Nusselt number, the friction factor, and the flow pattern. The computations have been run by Galerkin finite element method along with the Newton-Raphson iterative approach.

\section{Mathematical foundation and boundary conditions}

For incompressible steady flow, the governing equations can be written as:

$\frac{\partial}{\partial x_{i}}\left(\rho u_{i}\right)=0$

$\frac{\partial}{\partial x_{j}}\left(\rho u_{i} u_{j}\right)=-\frac{\partial p}{\partial x_{i}}+\frac{\partial}{\partial x_{j}}\left[\mu\left(\frac{\partial u_{i}}{\partial x_{j}}+\frac{\partial u_{j}}{\partial x_{i}}\right)\right]$

$\frac{\partial}{\partial x_{j}}\left(\rho u_{i} T\right)=\frac{\partial}{\partial x_{j}}\left(\frac{\mu}{\operatorname{Pr}} \frac{\partial T}{\partial x_{j}}\right)$

The local Nusselt number and friction factor are calculated as:

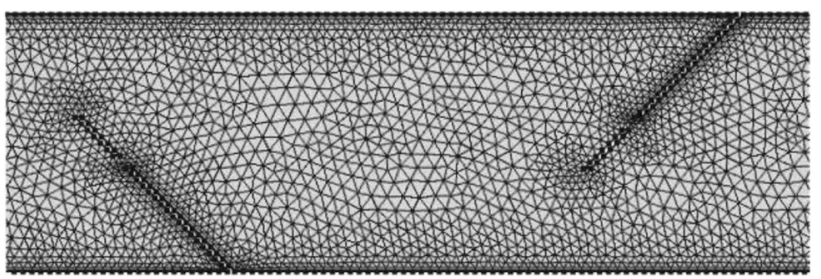

Fig. 1 A part of the computational domain with unstructured grids for baffles and channel $S=0.2, B R=0.6, \phi=45^{\circ}$

\section{Numerical results and discussion}

The variation of Nusselt number is shown in Fig. 2 for different grids. The difference in the Nusselt number and friction factor between the grid with 20,236 and 28,577 elements is negligible, hence the grid with 20,236 elements was adopted. The computational domain and boundaries are shown in Fig. 3. Air passing two-dimensional channel with a height of $20 \mathrm{~cm}$ and a length of $1 \mathrm{~cm}$. At the inlet, a parabolic velocity profile was specified; while a uniform temperature $T_{\text {in }}=300$ was assumed. The constant temperature of the bottom and upper wall is $T_{w}=375$. At the walls, the no-slip condition was

$N u=\frac{h_{x} D_{h}}{k}, \quad h_{x}=\frac{q_{w}}{T_{w}-T_{m}}, \quad T_{m}=\frac{\int_{0}^{H} u T d y}{\int_{0}^{H} u d y} ; \quad f=\frac{\Delta p\left(D_{h}\right)}{0.5 L \rho(\bar{U})^{2}}, \quad \bar{U}=\left(\frac{\int_{0}^{H} u d y}{\mathrm{H}}\right)_{x=0}$

The governing equations are solved by Finite element method. This method is the most generally used scheme for solving problems of engineering and mathematical models. Typical problem areas of interest include the traditional fields of structural analysis, heat transfer, fluid flow. The finite element method formulation lastly gets to a system of algebraic equations. By employing the Galerkin weighted residual approach, Eq. (1) take the form of non-linear assembled integral matrix equations. There is a standard procedure in evaluating the above integrations, which is mentioned by Taylor and Hughes. The resultant non-linear matrix equations are solved by a Newton-Raphson iterative process. At first, the velocity and pressure domains were obtained numerically. Since the solution of the energy equation depends on the velocity field, after getting this field, the energy equation was solved. The finite element pair for velocity and pressure LBB checked, and it was stable. Since our problem is convection dominated, the applied scheme (upwind-based) was stable. For achieving grid independence, the numerical tests have been carried out for different grids, as shown in Fig. 1. applied. The computational domain was chosen large enough to eliminate end effects. The $b_{t}$ is the hole height (shown in Fig. 3), and its value is $0.05 \mathrm{H}$.

The Nusselt numbers and friction factor are validated using the results of shah [20] for a rectangular-channel without baffle. The results are found to be in a good agreement for the plained channel with that of Shah [20], as shown in Figs. 4 and 5.

Figure 6 shows streamlines for the channel with two plain or perforated baffles vertically mounted on the channel wall with $\mathrm{BR}=0.6$ and $\mathrm{Re}=100$. Streamlines for the channel with two plain baffles are shown in Fig. 6a, $b$ indicates the effect of the baffle orientation on the streamlines. The streamlines of Fig. $6 \mathrm{~b}$ shows how the perforated baffle can change the recirculation zone in comparison with plain ones. In all cases, strong vortices are observed between two baffles and downstream of the second baffle. The height of the vortex between two baffles was nearly equal to the first baffle height. This recirculation zone is compressed by the upper baffle when the baffle rotated $45^{\circ}$ towards the channel inlet, the reattachment point downstream of the top baffle moves upstream. In Fig. $6 \mathrm{c}$ the hole in the baffle leads 
Fig. 2 Variation of Nusselt number for different grid sizes at $\operatorname{Re}=100$
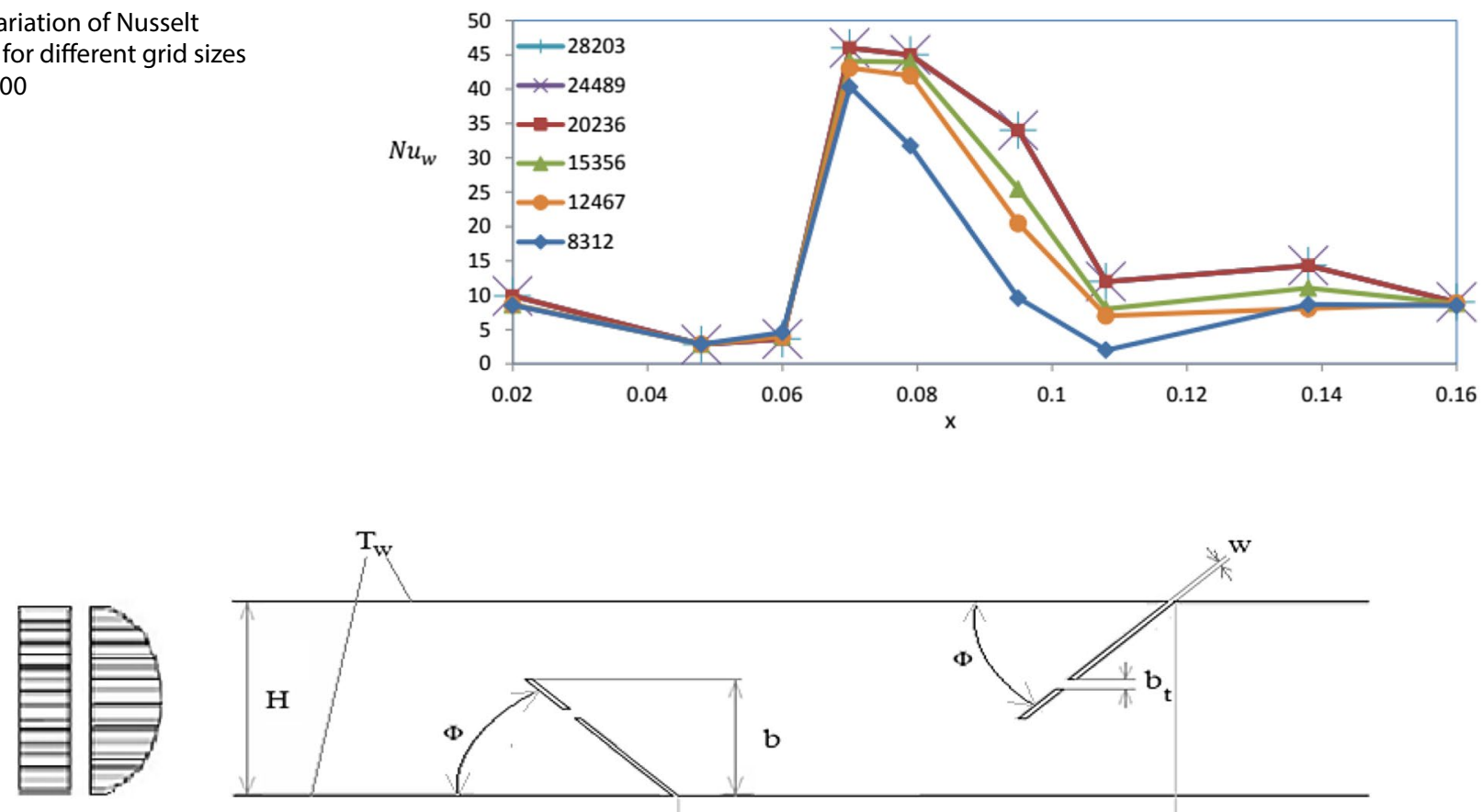

$\mathrm{T}_{\text {in }} \mathrm{u}_{\text {in }}$

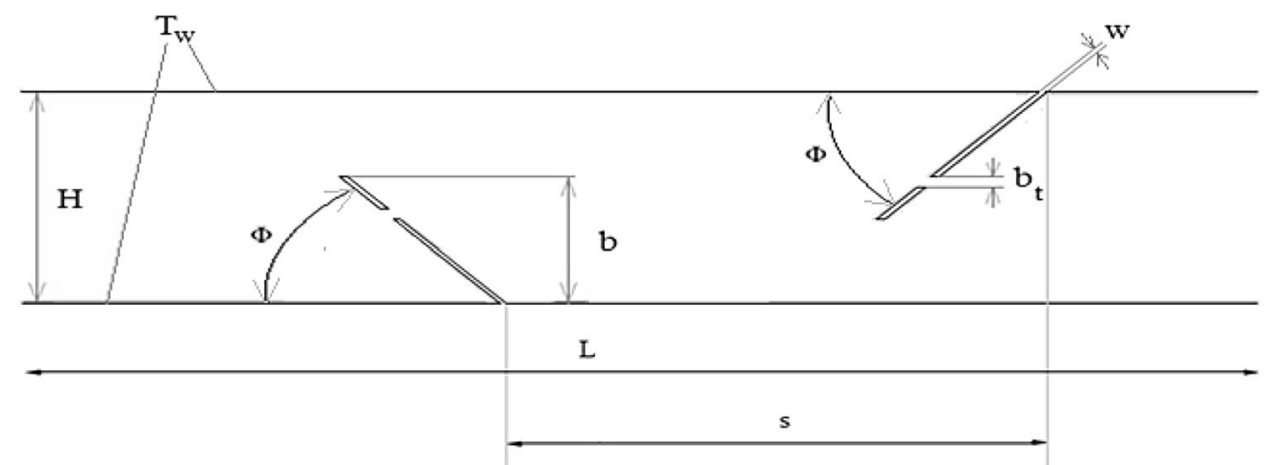

Fig. 3 Configuration of perforated inclined baffles and channel geometry

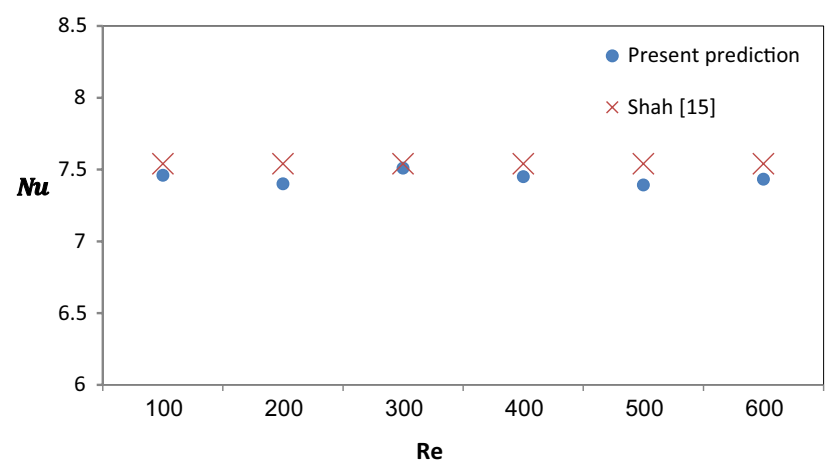

Fig. 4 Comparison of mean Nusselt numbers obtained for present work with that of Shah [20]

to a reduction in the deflection of streamlines. In Fig. 6a, $b$, the second vortices appear. The inclined baffles cause second vortices downstream of the baffles. The circulation created by second vortices increases the friction factor and heat transfer rate.

The ratios of mean friction factor for the channel without baffle and with baffle $\left(\frac{f}{f_{0}}\right)$ at different Reynolds num-

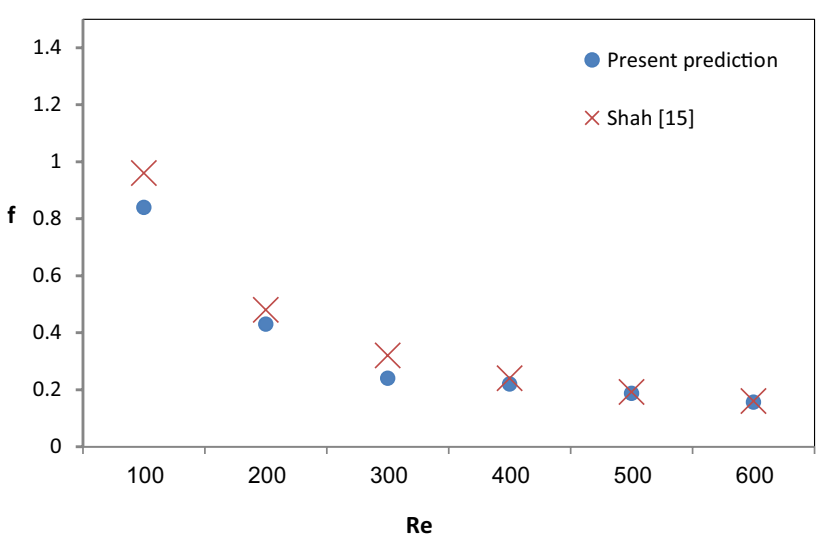

Fig. 5 Comparison of mean friction factor of current work with that of Shah [20]

bers and baffle angles are shown in Fig. 7. The increment of $\frac{f}{f_{0}}$ leads to Reynolds number rise. The $\frac{f}{f_{0}}$ for plain baffle is more than perforated baffle at different baffle angles.

The ratios of mean friction factor for the channel without baffle and with baffle $\left(\frac{f}{f_{0}}\right)$ at different Reynolds numbers and BRs are shown in Figs. 7 and 8 . The $\frac{f}{f_{0}}$ for plain 
(a)

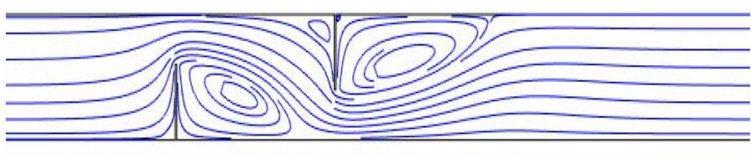

(b)

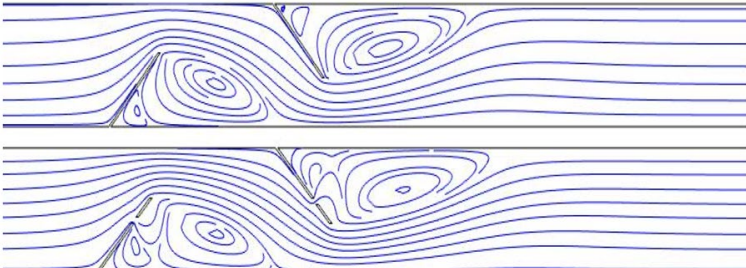

Fig. 6 Effects of baffle inclination (with or without hole) on the streamlines at $\mathrm{Re}=100, \mathrm{~S}=2, \mathrm{BR}=0.6$ a plain baffle, $\mathbf{b} 135^{\circ}$ baffle orientation, $\mathbf{c} 135^{\circ}$ perforated baffle baffle is more than perforated baffle at different Reynolds numbers. The $\frac{f}{f_{0}}$ increases when BR increases.

A change in the local Nusselt number will alter the temperature field. Figure 9 presents the variations of the local Nusselt number at the bottom wall for some inclination of plain baffles ( $B R=0.6, S=2)$. This figure shows that the downstream vortices make a significant effect on the local Nusselt number because they mix the fluid between the wall and the middle region. Between the channel inlet and the first baffle, the local Nusselt number decreases with low slop, when it reaches the vicinity of the first baffle. Figure 9 shows that the peak values of the Nusselt number in varying inclination angles located nearly at the same place because the vortices occur there. This figure shows that the existence of a vortex could enhance the Nusselt number. Variation of Nusselt number for the down wall at
Fig. $7 \frac{f}{f_{0}}$ for plain and perforated baffles at different baffles angles and $\mathrm{BR}=0.4$

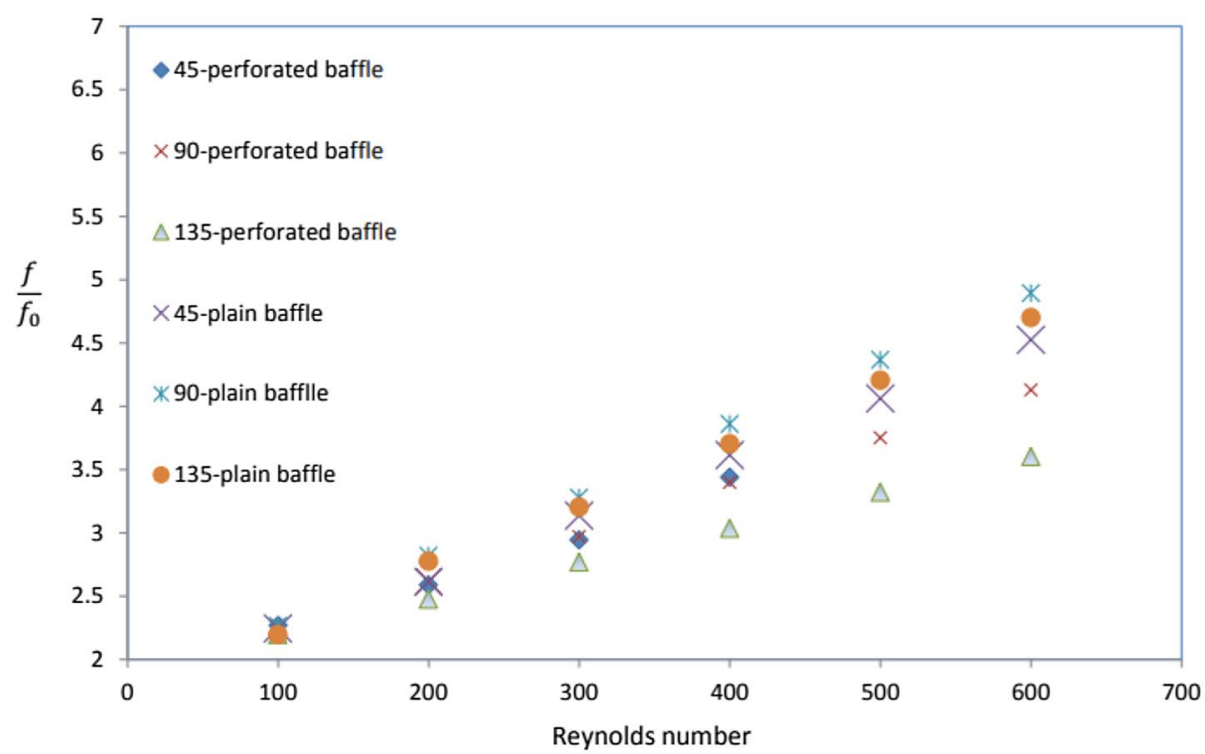

Fig. $8 \frac{f}{f_{0}}$ for plain and perforated baffles at different BRs and $\phi=45$

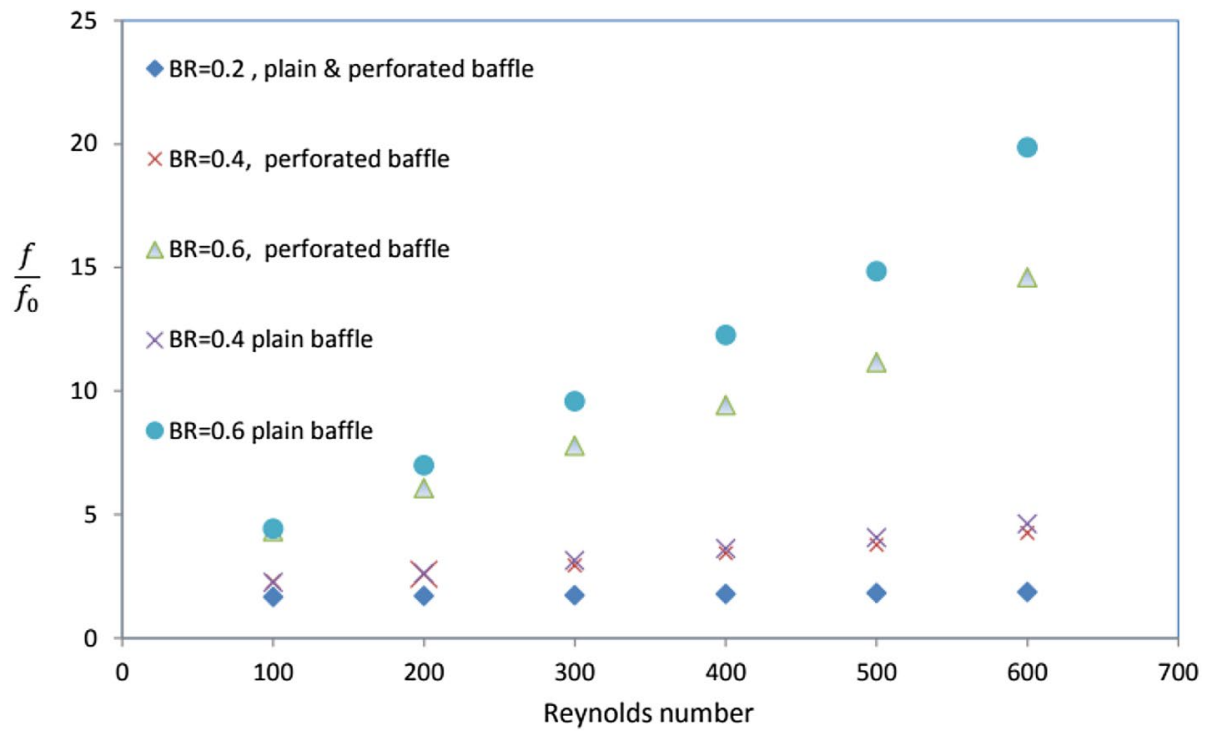

SN Applied Sciences 
Fig. 9 Distributions of local Nusselt numbers for plain baffles at different baffle angles, $\mathrm{BR}=0.6$, and $\mathrm{Re}=100$

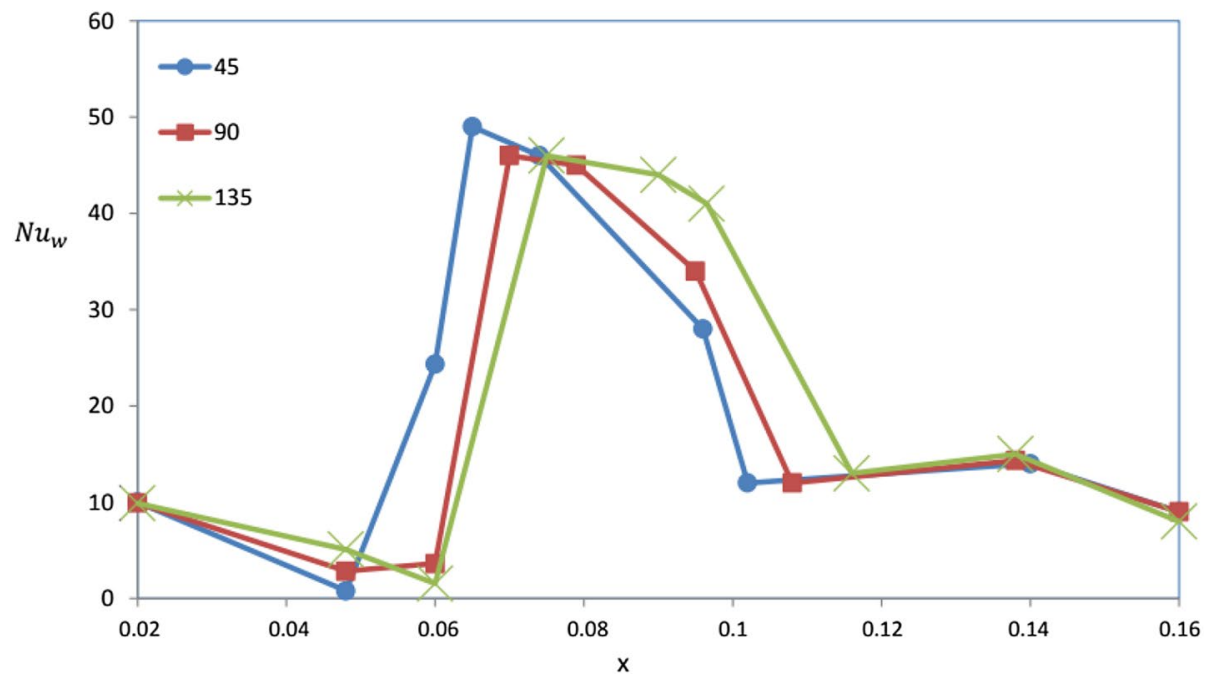

Fig. 10 Distributions of local Nusselt numbers for perforated baffles at different baffle angles, $\mathrm{BR}=0.6$, and $\mathrm{Re}=100$

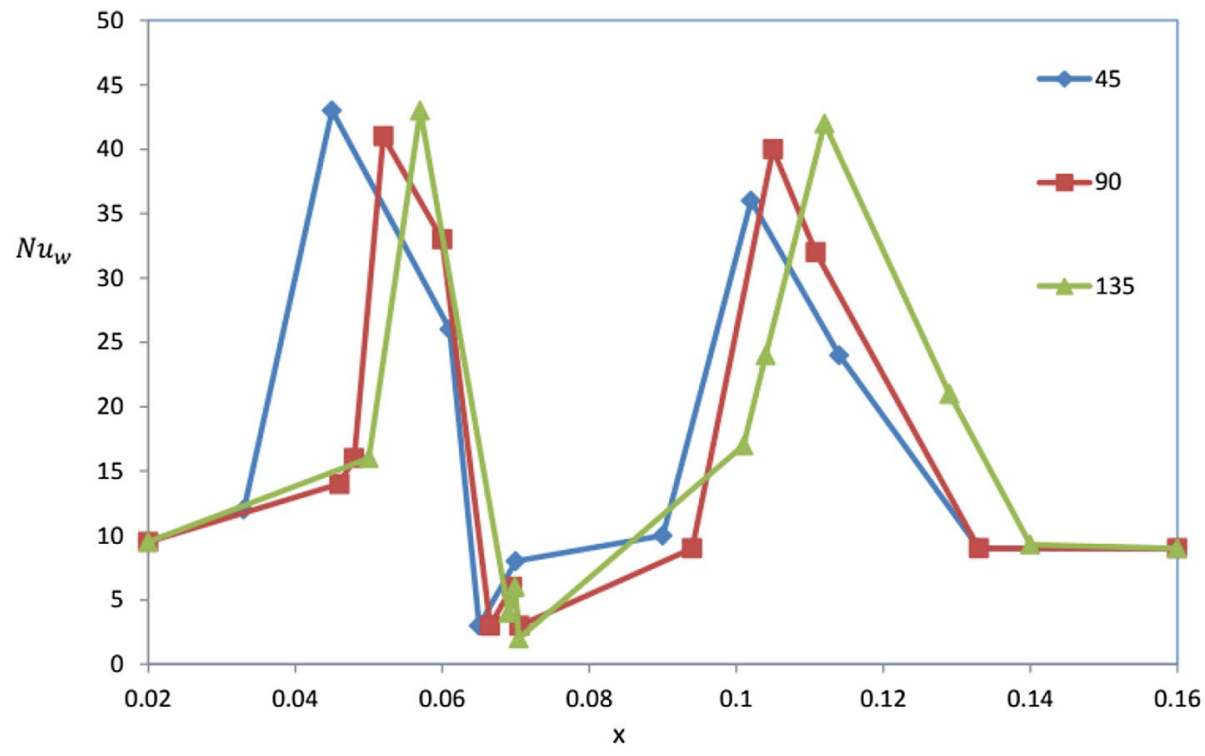

perforated baffles is shown in Fig. 10. This curve has different extremums. In other words, the change of the Nusselt number in this situation is complicated. Various parameters such as baffles location, affect the Nusselt number.

Comparison of mean Nusselt number $(\overline{\mathrm{Nu}})$ for perforated and plain baffles are shown in Figs. 11 and 12. The $\overline{N u}$ increases when Reynolds number rises.

The $\overline{\boldsymbol{N u}}$ and $\overline{\boldsymbol{f}}$ are considered essential factors in channels; therefore, the efficiency of baffles is defined to be $\eta=\frac{N u / N u_{0}}{\left(f / f_{0}\right)^{1 / 3}}$ which resembles a kind of Reynolds analogy.

The efficiency is calculated for different baffles, baffle angle, Reynolds number, and BRs. The estimated efficiency is shown in Fig. 13. When efficiency is lower than 1 , using the baffle is not appropriate. As observed in Fig. 13, the efficiency takes more than one in most cases. The efficiency elevates when Reynolds number increases. As a result, using baffles at high Reynolds numbers looks more economical. The efficiency of perforated baffles is more than that of plain baffles in most cases. The maximum efficiency happens for $\phi=135^{\circ}$.

According to the obtained results, the below correlation is proposed to calculate the efficiency in different conditions. The efficiency is the function of the Reynolds number and the baffle angle.

$\eta_{p l}=0.0005 R e+0.001 \varphi+0.8$

$\eta_{p e}=0.0008 R e+0.001 \varphi+0.8$

Two validations are done for the pure channel in this paper. For more certainty, our results for the channel with a baffle are compared with that of Cheng and Huang [2] in Fig. 14. 
Fig. 11 Comparison of mean Nusselt number at the down wall for perforated and plain baffles
Fig. 12 Comparison of mean Nusselt number at up wall for perforated and plain baffles
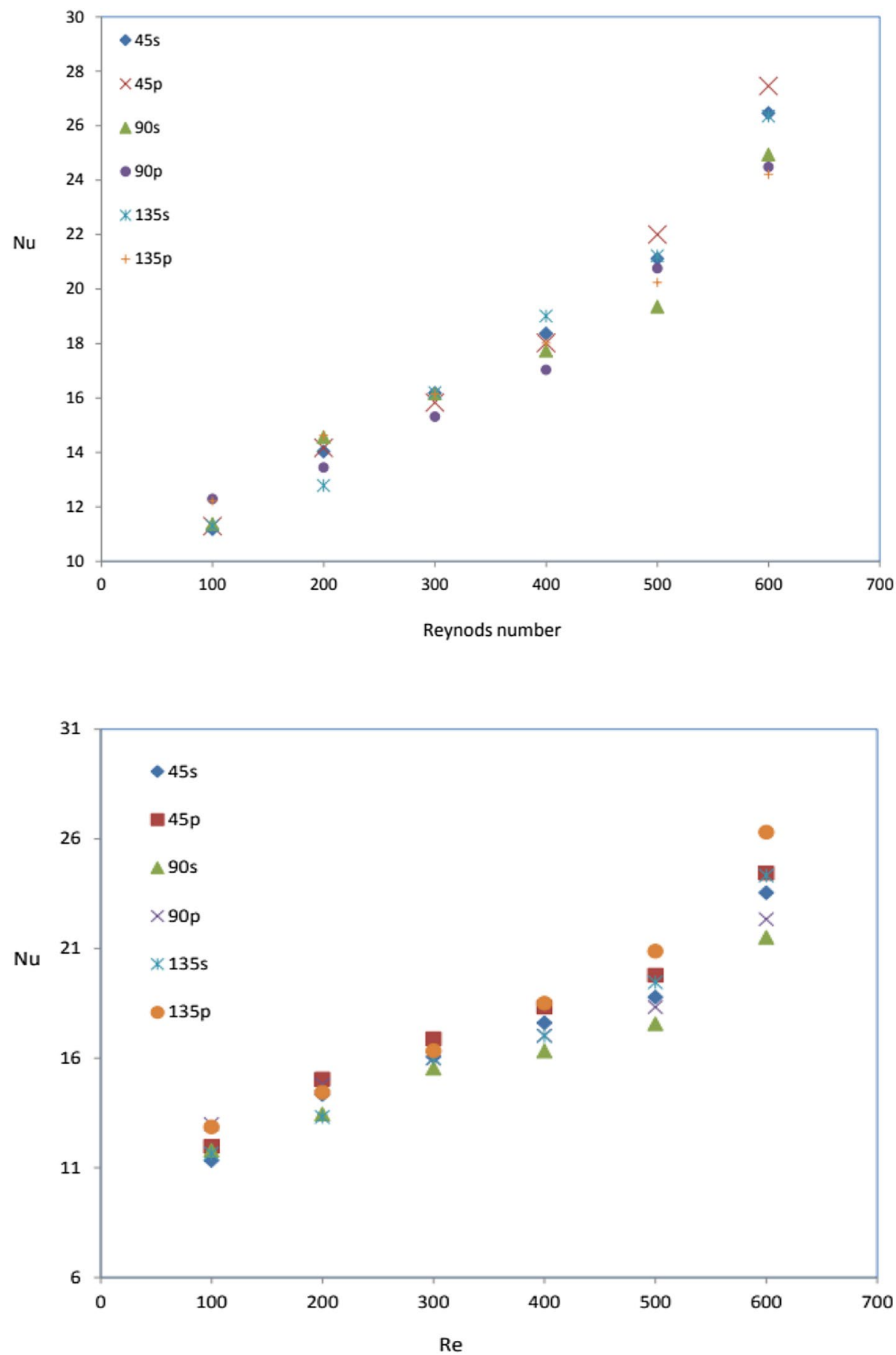

\section{Concluding remarks}

In this paper, two-dimensional incompressible flow between bare channel and channels with plain and perforated baffles are simulated numerically. Baffles were used with different angles. Simulation has been done for various Reynolds numbers. For all the cases considered here, the Nusselt number for the $135^{\circ}$ perforated baffles were found to be higher than those for other baffle angles. The primary vortices created by the baffles induce impingement flows on the sidewall and wall in the baffle cavity leading to an increase in heat transfer. There is local heat transfer enhancement at the downstream of the stepped baffle caused by the impinging effect of flow, which is even more significant when baffle height becomes higher or the Reynolds number 


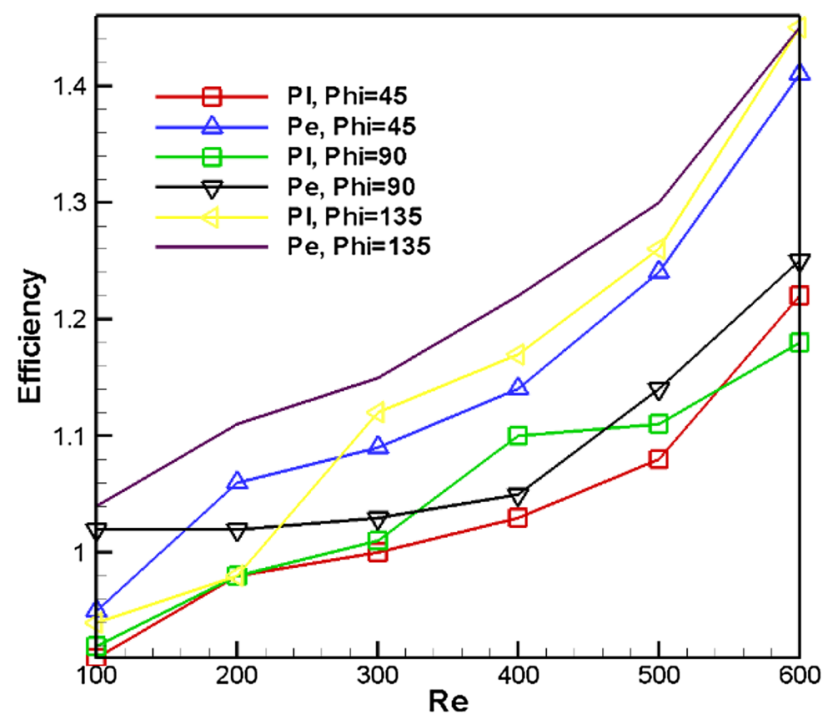

Fig. 13 Efficiency for different baffles, baffle angle, Reynolds number, and $\mathrm{BR}=0.6$

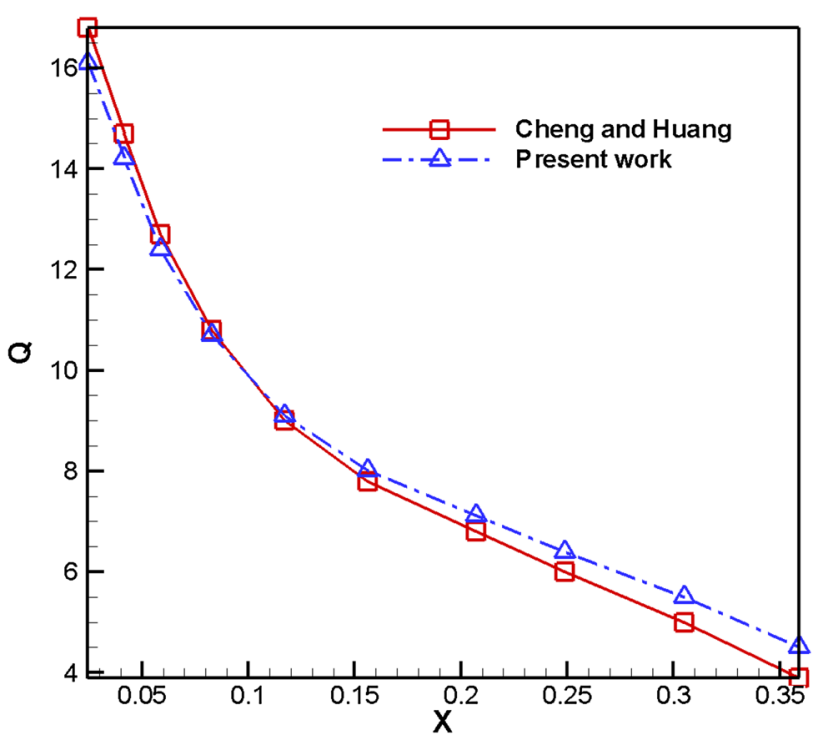

Fig. 14 Efficiency for different baffles, baffle angle, Reynolds number, and $B R=0.6$

elevates. The results also suggest that a $135^{\circ}$ perforated baffle is a better choice as it enhances the heat transfer with a minimal friction factor. The efficiency grows when the Reynolds number goes up.

\section{Compliance with ethical standards}

Conflict of interest The author(s) declare that they have no conflict of interests.

\section{References}

1. Armaly BF, Durst F, Pereira JCF, Schönung B (2006) Experimental and theoretical investigation of backward-facing step flow. J Fluid Mech 127:473-496. https://doi.org/10.1017/S002211208 3002839

2. Cheng C-H, Huang W-H (1989) Laminar forced convection flows in horizontal channels with transverse fins placed in entrance regions. Numer Heat Transf A Appl 16(1):77-100. https://doi. org/10.1080/10407788908944707

3. Dutta P, Dutta S (1998) Effect of baffle size, perforation, and orientation on internal heat transfer enhancement. Int J Heat Mass Transf 41(19):3005-3013. https://doi.org/10.1016/S0017 -9310(98)00016-7

4. Lopez JR, Anand NK, Fletcher LS (1996) Heat transfer in a threedimensional channel with baffles. Numer Heat Transf A Appl 30(2):189-205. https://doi.org/10.1080/10407789608913835

5. Da Silva Miranda BM, Anand NK (2004) Convective heat transfer in a channel with porous baffles. Numer Heat Transf A Appl 46(5):425-452. https://doi.org/10.1080/10407780490478515

6. Mousavi SS, Hooman K (2006) Heat and fluid flow in entrance region of a channel with staggered baffles. Energy Convers Manag 47(15):2011-2019. https://doi.org/10.1016/j.encon man.2005.12.018

7. Nasiruddin Siddiqui MHK (2007) Heat transfer augmentation in a heat exchanger tube using a baffle. Int J Heat Fluid Flow 28(2):318-328. https://doi.org/10.1016/j.ijheatfluidflow .2006 .03 .020

8. Sripattanapipat S, Promvonge P (2009) Numerical analysis of laminar heat transfer in a channel with diamond-shaped baffles. Int Commun Heat Mass Transf 36(1):32-38. https://doi. org/10.1016/j.icheatmasstransfer.2008.09.008

9. Promvonge P, Sripattanapipat S, Kwankaomeng S (2010) Laminar periodic flow and heat transfer in square channel with 45 inline baffles on two opposite walls. Int J Therm Sci 49:963-975. https://doi.org/10.1016/j.ijthermalsci.2010.01.005

10. Gajusingh ST, Shaikh N, Siddiqui K (2010) Influence of a rectangular baffle on the downstream flow structure. Exp Therm Fluid Sci 34(5):590-602. https://doi.org/10.1016/j.expthermfl usci.2009.11.011

11. Huang KD, Tzeng S-C, Jeng T-M, Wang J-R, Cheng S-Y, Tseng K-T (2008) Experimental study of fluid flow and heat transfer characteristics in the square channel with a perforation baffle. Int Commun Heat Mass Transf 35(9):1106-1112. https://doi. org/10.1016/j.icheatmasstransfer.2008.07.013

12. Chompookham T, Thianpong C, Kwankaomeng S, Promvonge $P(2010)$ Heat transfer augmentation in a wedge-ribbed channel using winglet vortex generators. Int Commun Heat Mass Transf 37(2):163-169. https://doi.org/10.1016/j.icheatmasstrans fer.2009.09.012

13. Benzenine $H$, Saim $R$, Abboudi S, Imine O, Oztop HF, AbuHamdeh N (2018) Numerical study of a three-dimensional 
forced laminar flow in a channel equipped with a perforated baffle. Numer Heat Transf A Appl 73(12):881-894. https://doi. org/10.1080/10407782.2018.1486645

14. Adibi T, Adibi O, Razavi SE (2019) A characteristic-based solution of forced and free convection in closed domains with emphasis on various fluids. Int J Eng 32(10):1679-1685. https://doi. org/10.5829/ije.2019.32.11b.20

15. Adibi T, Razavi SE, Adibi O (2020) A characteristic-based numerical simulation of water-titanium dioxide nano-fluid in closed domains. Int J Eng 33(1):158-163. https://doi.org/10.5829/ ije.2020.33.01a.18

16. Menni Y, Azzi A, Chamkha AJ (2018) Optimal thermo aerodynamic performance of $s$-shaped baffled channels. J Mech Eng Sci 12(3):3888-3913. https://doi.org/10.15282/ jmes.12.3.2018.10.0341

17. Sahin B, Ates I, Manay E, Bayrakceken A, Celik C (2019) Optimization of design parameters for heat transfer and friction factor in a heat sink with hollow trapezoidal baffles. Appl Therm Eng 154:76-86. https://doi.org/10.1016/j.appltherma leng.2019.03.056

18. Foukrach $\mathrm{M}$, Ameur $\mathrm{H}$ (2019) Effect of baffles shape on the flow patterns and power consumption in stirred vessels. SN Appl Sci 1(11):1503. https://doi.org/10.1007/s42452-019-1550-9

19. Shiriny A, Bayareh M, Ahmadi Nadooshan A, Bahrami D (2019) Forced convection heat transfer of water/FMWCNT nanofluid in a microchannel with triangular ribs. SN Appl Sci 1(12):1631. https://doi.org/10.1007/s42452-019-1678-7

20. Shah RK (1975) Laminar flow friction and forced convection heat transfer in ducts of arbitrary geometry. Int J Heat Mass Transf 18(7):849-862. https://doi.org/10.1016/0017-9310(75)90176-3

Publisher's Note Springer Nature remains neutral with regard to jurisdictional claims in published maps and institutional affiliations. 